Teodoro, A.P.E.G.; Kawaguti, C.N.; Trevisan, P.R.T.C.; Christofoletti, D.A. Ecoturismo e ambiente virtual: pesquisa sobre fatores desencadeadores de adesão à prática. Anais do VIII Congresso Nacional de Ecoturismo e do IV Encontro Interdisciplinar de Ecoturismo em Unidades de Conservação. Revista Brasileira de Ecoturismo, São Paulo, v.4, n.4, 2011, p. 558.

\title{
ECOTURISMO E AMBIENTE VIRTUAL: PESQUISA SOBRE FATORES DESENCADEADORES DE ADESÃO À PRÁTICA
}

\section{Ana Paula Evaristo Guizarde Teodoro*, Cristiane Naomi Kawaguti*, Priscila Raquel Tedesco da Costa Trevisan*, Danielle Auriemo Christofoletti*}

\author{
Universidade Estadual Júlio de Mesquita Filho - Câmpus Rio Claro \\ anapaulaguizarde@yahoo.com.br, (?), priscila@lancernet.com.br, \\ daniauriemo@yahoo.com.br
}

O desenvolvimento tecnológico, característico da contemporaneidade, permitiu avanços em diversos campos da ação humana, tendo ressonâncias, inclusive, no aspecto de gestão, organização e disseminação do ecoturismo. Com as novas tecnologias envolvidas na criação dos equipamentos de segurança, bem como, com a melhoria na divulgação das atividades ecoturísticas, o mercado referente ao Turismo de Aventura apresenta demanda crescente. Entretanto, ainda que este crescimento seja um fato, poucos estudos, na literatura científica, focalizam o olhar sobre o impacto dessas tecnologias, bem como, das tecnologias de comunicação nesse segmento, o que motivou o interesse deste estudo em buscar compreender esse aspecto. O estudo, de natureza qualitativa, investigou o papel da mídia virtual na escolha de atividades ecoturísticas. Para tanto, utilizou-se uma pesquisa exploratória, desenvolvida por meio de um questionário aplicado online para uma amostra intencional composta por 20 membros de duas comunidades da rede social ORKUT relacionadas ao Ecoturismo e Aventura. Os dados foram analisados de forma descritiva, por meio da Técnica de Análise de Conteúdo Temático e indicam que o envolvimento com as atividades se inicia predominantemente pela busca de informações sobre diferentes atividades em sites de divulgação de locais e pólos de turismo de aventura. Posteriormente, a adesão se processa com a busca de sites de empresas especializadas que oferecem este tipo de atividade. A segurança e a atratividade do local são os aspectos primordiais levados em consideração pela maioria dos participantes, na escolha da atividade ecoturística. Este resultado aponta para a necessidade de maior valorização do ambiente virtual como veículo de divulgação sobre ecoturismo, no âmbito da gestão corporativa nesse segmento. Além disso, torna-se relevante valorizar o ambiente virtual como campo de pesquisa no Ecoturismo e Turismo de Aventura, no sentido de se compreender as nuances referentes ao processo de adesão a estas atividades.

Palavras-chave: Ecoturismo; Adesão; Virtual. 